\title{
Article
}

\section{Acetylcholine Regulates Olfactory Perceptual Learning through Effects on Adult Neurogenesis}

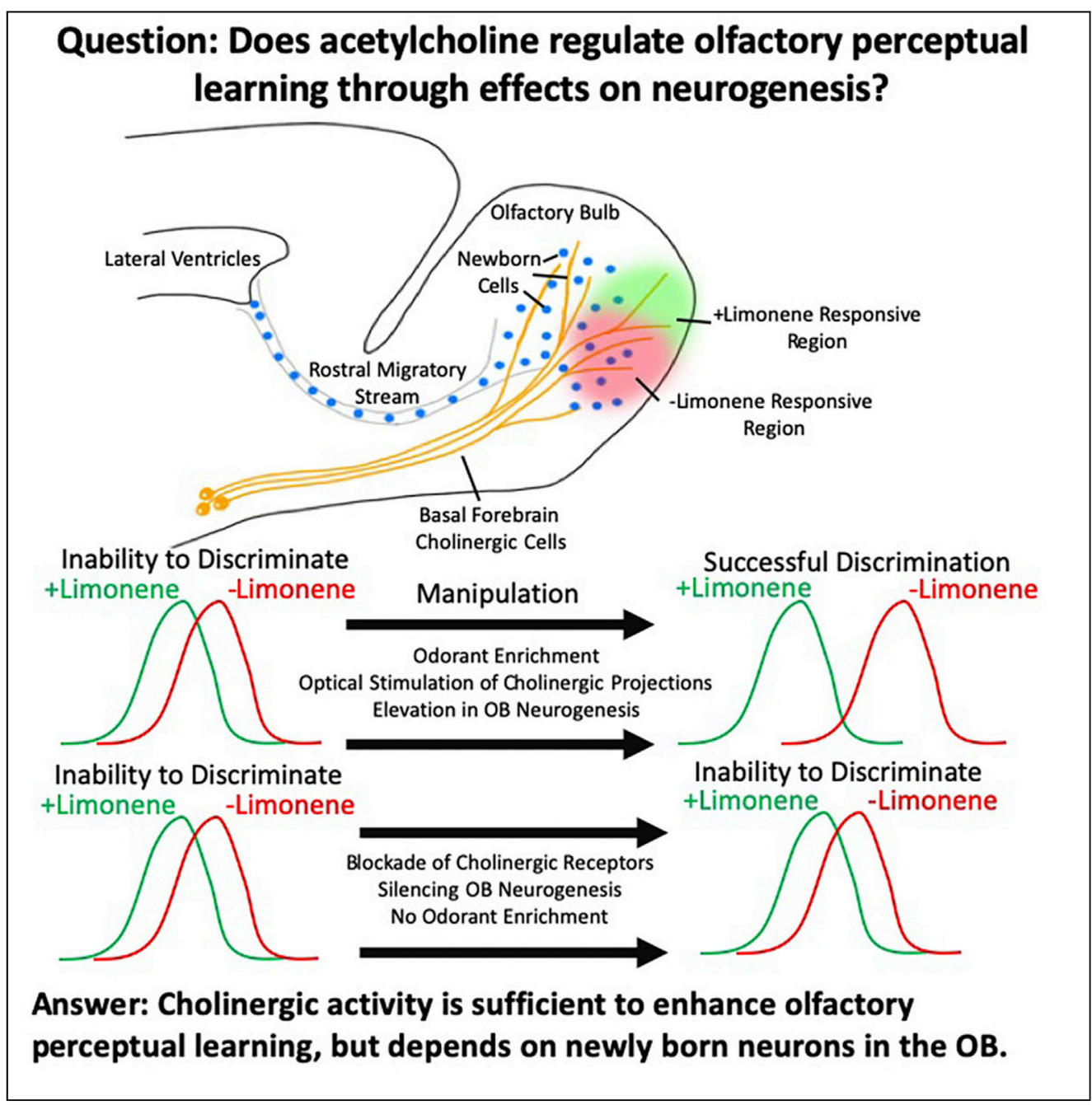

Arielle Schilit

Nitenson,

Gabriela Manzano

Nieves, Devon

Lynn Poeta, Ryan

Bahar, Carolyn

Rachofsky,

Nathalie

Mandairon, Kevin

G. Bath

kevin_bath@brown.edu

HIGHLIGHTS

Acetylcholine modulates

olfactory perceptual

learning

Cholinergic modulation alters olfactory bulb

neurogenesis

Cholinergic effects on olfactory perceptual

learning require adult neurogenesis

Cholinergic excitation does not alter the phenotype of newborn olfactory bulb cells 


\title{
Article
}

\section{Acetylcholine Regulates Olfactory Perceptual Learning through Effects on Adult Neurogenesis}

\author{
Arielle Schilit Nitenson, ${ }^{1,4}$ Gabriela Manzano Nieves, ${ }^{1,4}$ Devon Lynn Poeta, ${ }^{2}$ Ryan Bahar, ${ }^{1}$ Carolyn Rachofsky, \\ Nathalie Mandairon, ${ }^{3}$ and Kevin G. Bath ${ }^{2,5, *}$
}

\begin{abstract}
SUMMARY
Learning to perceptually discriminate between chemical signals in the environment (olfactory perceptual learning [OPL]) is critical for survival. Multiple mechanisms have been implicated in OPL, including modulation of neurogenesis and manipulation of cholinergic activity. However, whether these represent distinct processes regulating OPL or if cholinergic effects on OPL depend upon neurogenesis has remained an unresolved question. Using a combination of pharmacological and optogenetic approaches, cholinergic activity was shown to be both necessary and sufficient to drive OPL, and this process was dependent on the presence of newly born cells in the olfactory bulb (OB). This study is the first to directly demonstrate that cholinergic effects on OPL require adult $O B$ neurogenesis.
\end{abstract}

\section{INTRODUCTION}

In many species, olfaction supports basic processes such as navigation, copulation, social bonding, predator avoidance, and foraging behaviors. To accomplish this, the olfactory system must sense and discriminate countless potential chemical signals in the environment and rapidly adapt to the changing chemical landscape. The acquired ability to discriminate between highly similar chemical signals has been termed olfactory perceptual learning (Linster et al., 2001a; Fletcher and Wilson, 2002; Wilson and Stevenson, 2003). The basic mechanisms that govern olfactory perceptual learning (OPL) remain poorly understood but have the potential to shed light on the mechanisms underlying one of the most basic and critical learning processes supporting survival and adaptation.

Odorants bind to olfactory receptors in the olfactory epithelium that synapse onto mitral/tufted cells within the olfactory bulb (OB). These cells send projections to the cortex, where odors are perceived. Two types of GABAergic inhibitory interneurons, periglomerular and granule cells, assist in tuning mitral cell outputs of the OB to support perceptual discrimination (Mori et al., 1999; Restrepo, 2009; Tan et al., 2010). These cells are continually produced in the subventricular zone (SVZ) of the lateral ventricles at high rates throughout life (Altman and Das, 1965; Altman, 1969). Newly born cells of the SVZ migrate to the OB where they have been implicated in regulating OB sensory function and plasticity (Bath et al., 2008; Mouret et al., 2008; Moreno et al., 2009, 2012; Nissant et al., 2009; Alonso et al., 2012; Gheusi and Lledo, 2014). A multitude of potential signaling pathways have been implicated in the birth, migration, and survival of newly born cells in the OB. However, the pathways recruited to support shifts in cell survival following experience to alter $O B$ function remain unclear. A strong candidate to mediate this function is the cholinergic system.

Acetylcholine has been implicated in the regulation of the birth, migration, and survival of newly born granule and periglomerular cells in the $\mathrm{OB}$. Blocking the degradation of acetylcholine leads to an increase in the density of newly born OB granule cells (Kaneko et al., 2006), whereas lesioning basal forebrain cholinergic cells is associated with a decrease in the density of newly born granule cells in the OB (Cooper-Kuhn et al., 2004). More recent work has found that cholinergic receptors are critical for regulating the proliferation and migration of newly born cells (Sharma, 2013; Paez-Gonzalez et al., 2014). Cholinergic projections to the $O B$ have also been shown to sharpen the tuning of mitral cells by increasing and broadening the responsiveness of granule cells as well as enhancing periglomerular cell inhibition of mitral cells (Heimer et al., 1990; Castillo et al., 1999; Linster and Cleland, 2002;
1 Department of Neuroscience, Brown University, Providence, RI 02912, USA

2Department of Cognitive, Linguistic and Psychological Sciences, Brown University, 190 Thayer St., Box 1821, Providence, RI 02912, USA

3INSERM, U1028, CNRS, UMR5292, Lyon

Neuroscience Research Center, Lyon 69000, France

${ }^{4}$ These authors contributed equally

${ }^{5}$ Lead Contact

*Correspondence: kevin_bath@brown.edu https://doi.org/10.1016/j.isci. 2019.11.016 
Chaudhury et al., 2009; Ma and Luo, 2012). Stimulation of cholinergic projections to the OB leads to sparser mitral cell activation, increased separation in spatial coding of odorants at the level of the $O B$, and improved odorant perceptual discrimination in both in vivo and modeling work (Linster and Hasselmo, 1997; Stopfer et al., 1997; Nusser et al., 2001; Cleland and Sethupathy, 2006; Mandairon et al., 2006a; Chaudhury et al., 2009; Linster and Cleland, 2009; Cleland and Linster, 2012). Although it is clear that acetylcholine can influence processes associated with neurogenesis and perceptual discrimination, it is not known if these effects are mutually independent or function together to govern more lasting changes, such as those that support OPL. In this study, we sought to test if cholinergic activity functions through the modulation of neurogenesis to support OPL.

We used pharmacological and optogenetic approaches to manipulate cholinergic activity and assessed changes in OPL, adult neurogenesis, and general olfactory function. In an OPL paradigm, transient pharmacological attenuation of cholinergic activity during olfactory enrichment inhibited OPL. Interestingly, the decrease in the ability of mice to discriminate enantiomer pairs (molecules that are structurally mirror images of one another) was accompanied by a significant reduction in newly born OB cells. Furthermore, stimulation of cholinergic inputs into the OB was sufficient to induce OPL (discrimination of enantiomer pairs) in the absence of odorant enrichment. To draw a more direct relationship between cholinergic modulation and neurogenesis, a mitotic blocker, cytosine arabinoside (AraC), was continuously delivered into a lateral ventricle, inhibiting neurogenesis during the period of optogenetic stimulation of cholinergic fibers to the OB. This manipulation blocked improvements in olfactory discrimination that were previously seen following an identical stimulation protocol. Together, these findings provide strong evidence indicating that the cholinergic system supports $O P L$ and that this process is dependent on the continued presence of newly born cells in the OB.

\section{RESULTS}

\section{Repeated Odorant Enrichment Is Sufficient to Support Olfactory Perceptual Learning}

Olfactory cross-habituation tasks are used to assess the degree to which mice can spontaneously discriminate between odorants (Cleland et al., 2002; Mandairon et al., 2006b; Bath et al., 2008; Moreno et al., 2009). In mice, repeated odorant exposure over multiple trials leads to attenuated investigation time (time sniffing within 1 inch of the odorant) across trials, indicating successful habituation. When a new odorant is introduced, if investigation time increases (lack of cross-habituation or discrimination), this indicates successful perceptual differentiation from the original habituation odorant. If investigation time does not increase for the new odorant (cross-habituation), the animal is believed to have failed to discriminate between the habituated and novel odorant.

To test for olfactory perceptual learning (OPL), we employed an olfactory cross-habituation task to assess discrimination ability before and after an enrichment period to a pair of perceptually similar odorants (Mandairon et al., 2006b) (Figure 1A). Briefly, we tested the ability of mice to discriminate between three difficult to discriminate pairs of enantiomers over three consecutive days: + and - limonene, + and - carvone, and + and - terpinen-4-ol. Mice were habituated over four trials (5-min intertrial interval [ITI]) to the + form of the odorant diluted to $0.1 \mathrm{~Pa}$ in mineral oil (+ limonene, + carvone, or + terpinen-4-ol; Figure 1B left). Five minutes following the habituation trials, mice were presented with the - form of the odorant also diluted to $0.1 \mathrm{~Pa}$ (-limonene, -carvone, -terpinen-4-ol, respectively; Figure 1B right).

To assess if mice habituated to the odorants over the four trials of the first habituation, a two-way ANOVA was used. Testing revealed a significant effect of habituation $\left(F_{(3,132)}=19.58, p<0.0001\right)$, signifying that mice explored odorants for less time as trials progressed. A main effect of odorants $\left(F_{(2,132)}=13.76\right.$, $p<0.0001)$ was also observed, suggesting that mice spent more time sniffing some odorants compared with others. A post hoc Tukey's multiple comparison analysis revealed that mice spent more time sniffing the + limonene odorant compared with + carvone $\left(t_{132}=5.35, p=0.0007\right)$ and + terpinen-4-ol $\left(t_{132}=5.98\right.$, $p=0.0001$ ) on trial 1 of habituation. Furthermore, mice spent significantly more time sniffing + limonene when compared with + terpinen-4-ol $\left(t_{132}=3.40, p=0.045\right)$ on trial 3 of habituation. However, by trial 4 of habituation no significant differences were detected. In addition, no odorant by habituation interactions was observed $\left(F_{(6,132)}=1.42, p=0.21\right)$. To test if mice could discriminate between the $+/$ - enantiomer pairs before enrichment, mice were presented with the - enantiomer in a pretest. Mice were not able to discriminate between the + and - form of any of the enantiomer pairs (final habituation trial versus pretest 
A

Experimental Timeline

\begin{tabular}{|c|c|c|}
\hline $\begin{array}{c}\text { Habituation } \\
\text { Pretest }\end{array}$ & $\begin{array}{c}\text { Enrichment } \\
\text { Period }\end{array}$ & $\begin{array}{l}\text { Habituation } \\
\text { Posttest }\end{array}$ \\
\hline \begin{tabular}{ll|l|} 
& $\mathrm{C}$ & $\mathrm{T}$ \\
\end{tabular} & & \begin{tabular}{l|l}
$\mathrm{C}$ & $\mathrm{T}$ \\
\end{tabular} \\
\hline Days 1-3 & $12-22$ & $25-27$ \\
\hline
\end{tabular}

B
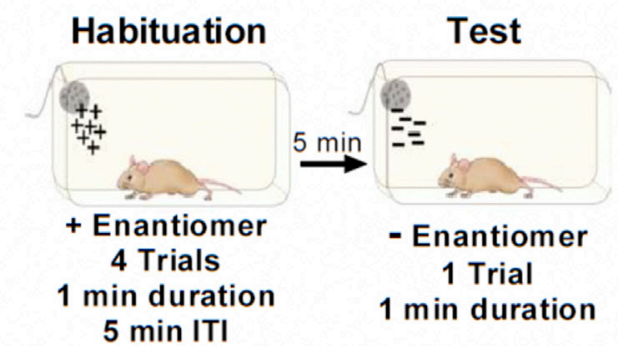

- Enantiomer

1 Trial

$1 \mathrm{~m}$ in duration
C Enrichment

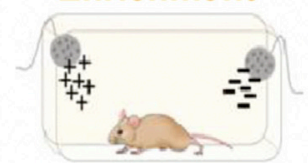

+ and - Enantiomers $1 \mathrm{hr}$ per day

D

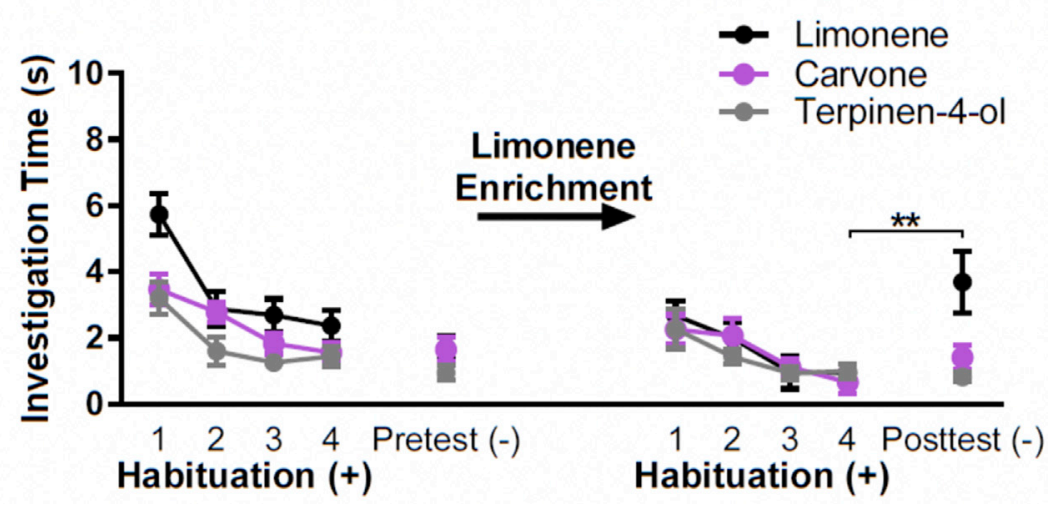

Figure 1. Odorant Enrichment Allowed Mice to Learn to Distinguish between Perceptually Similar Enantiomers (A) Experimental timeline ( $L$, limonene; $C$, carvone; $T$, terpinen-4-ol).

(B and C) (B) Depiction of olfactory perceptual learning and (C) enrichment protocols.

(D) Mice were unable to discriminate between the $+/$ - enantiomers during the pretest. However, following enrichment to + and - limonene, mice were able to discriminate between + and - limonene but not other enantiomer pairs during the posttest. For all groups $n=12$.

Data are presented as mean \pm SEM. ${ }^{* *} p<0.01$

trial: limonene $t_{22}=1.15, p=0.26$; carvone $t_{22}=0.85, p=0.85$; terpinen-4-ol $t_{22}=1.36, p=0.19$; Figure 1D). Mice then received olfactory enrichment for a period of ten consecutive days, where they were exposed to both the + and - undiluted forms of limonene for $1 \mathrm{~h}$ per day (Figure 1C). Following enrichment, mice underwent a second round of habituation to the + form of the three enantiomers on consecutive days (second habituation session). A main effect of habituation was revealed $\left(F_{(3,132)}=10.09, p<0.0001\right)$, signifying that mice habituated to odorants during post-enrichment habituation. No main effect of odorants $\left(F_{(2,132)}=\right.$ $0.34, p=0.70)$ or interaction between habituation and odorants $\left(F_{(6,132)}=0.36, p=0.89\right)$ was observed. Following the post-enrichment habituation bout, mice received a posttest for all three enantiomer pairs. Mice only learned to discriminate between + and - limonene, the enriched pair of odorants (limonene $t_{22}=2.87, p=0.009$; Figure $1 \mathrm{D}$ right), as evidenced by a significant increase in investigation between the final habituation trial and the posttest trial. Furthermore, enrichment with the limonene enantiomer pair, and pretesting with enantiomer pairs, did not enhance the ability of mice to discriminate between the enantiomer pairs for carvone $\left(t_{22}=1.53, p=0.14\right)$ or terpinen-4-ol $\left(t_{22}=0.65, p=0.53\right)$. Together these results indicate that enrichment enhanced discrimination abilities between enantiomer pairs and was selective to the enriching odorants. 
A

\section{Experimental Timeline}

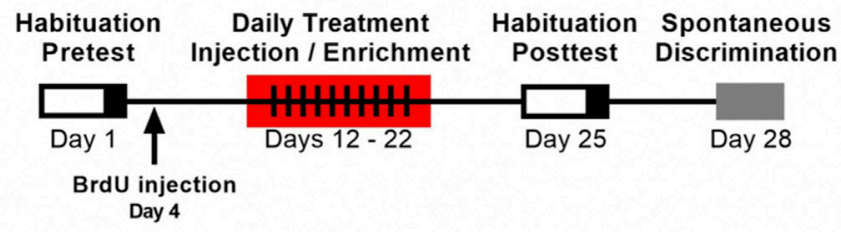

B

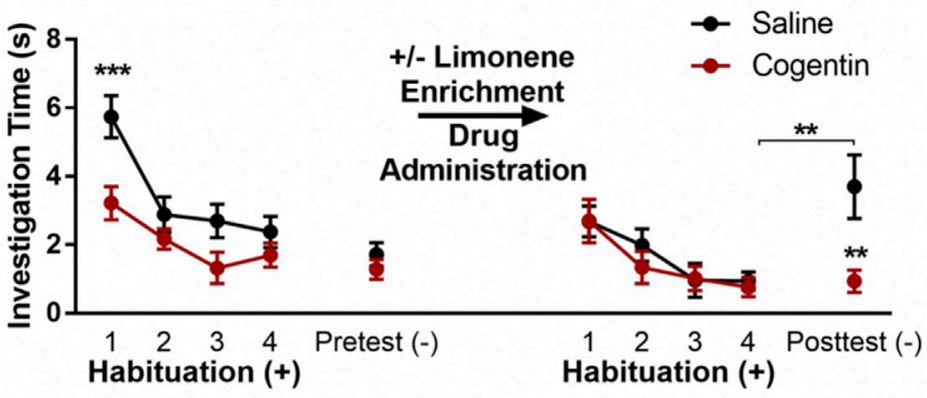

C

Spontaneous Olfactory Discrimination

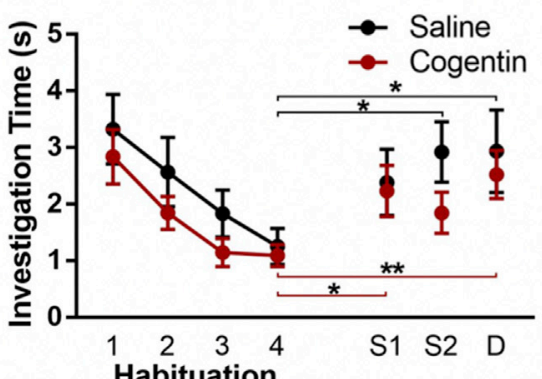

Habituation
D

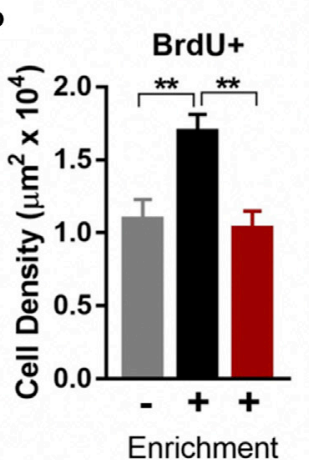

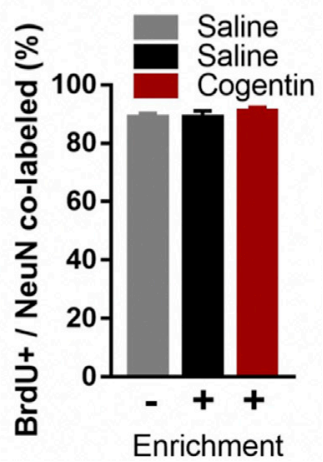

Figure 2. Pharmacological Treatment with Cogentin (a Cholinergic Antagonist) during Olfactory Enrichment Inhibits Olfactory Perceptual Learning

(A) Experimental timeline.

(B) Mice in neither the saline nor Cogentin group were able to discriminate between the $+/$ - enantiomers during the pretest. However, following enrichment to + and - limonene, saline- but not Cogentin-treated mice were able to discriminate between + and - limonene during the posttest.

(C) Cogentin treatment did not affect spontaneous olfactory discrimination. Saline $n=12$, Cogentin $n=9$.

(D) Olfactory enrichment increased BrdU+ cell density when compared with no-enrichment saline controls, whereas Cogentin significantly decreased BrdU + cell density when compared with enriched saline controls. Neither enrichment nor Cogentin treatment affected the percentage of newborn cells that became neurons (Saline no-enrichment $n=8$,

Saline enrichment $n=7$, Cogentin $n=7$ ).

Data are presented as mean \pm SEM. ${ }^{\star} p<0.05,{ }^{\star \star} p<0.01,{ }^{\star \star \star} p<0.001$.

Pharmacological Blockade of Select Cholinergic Receptors Inhibits Olfactory Perceptual Learning

Although modulation of cholinergic tone while animals are engaged in a discrimination task impacts odorant discrimination (Linster et al., 2001a; Mandairon et al., 2006a; Chaudhury et al., 2009), we are not aware of any studies that have specifically examined the role of acetylcholine on OPL. To determine if altering the activity of cholinergic receptors during olfactory enrichment impacts $\mathrm{OPL}$, mice were randomly assigned and administered the anticholinergic agent Benztropine Mesylate (Cogentin, $25 \mathrm{mg} / \mathrm{kg}$ ) or vehicle delivered i.p. 20 min before each +/- limonene olfactory enrichment session (Figure 2A). Cogentin inhibits muscarinic cholinergic receptors, an effect largely restricted to the central nervous system (Freedman et al., 1988; Bolden et al., 1992). After a 3-day washout period, mice underwent posttesting to assess their ability to discriminate between $+/-$ limonene (Figure 2B). 
We observed a significant main effect of group during the pretest, before our drug manipulation $\left(F_{(1,108)}=16.37, p<0.0001\right.$; Figure $\left.2 B\right)$. A Sidak's post hoc analysis revealed that the saline group spent significantly more time investigating + limonene only during trial 1 of the first habituation session $\left(t_{108}=3.859, p=0.0008\right)$. Importantly, no effect of group was observed for subsequent habituation trials or on investigation for the pretest enantiomer trial $\left(t_{27}=0.9806, p=0.3355\right)$. Furthermore, a main effect of habituation trial was observed, signifying that mice habituated to + limonene (two-way ANOVA; $F_{(3,108)}=12.82, p<0.0001$; Figure $2 B$ ). A failure to discriminate (e.g., cross-habituation) was observed in both the group that would subsequently receive saline $\left(t_{22}=1.15, p=0.26\right)$ and the group that would subsequently receive Cogentin ( $t_{32}=0.92, p=0.37$; Figure $2 \mathrm{~B}$ left). Mice then underwent daily saline or Cogentin injections 20 min before each daily +/- limonene enrichment session (total 10 days, Figure 2A). Three days following the last enrichment session and Cogentin injection, mice were again tested for discrimination abilities. For the habituation portion of the trial, there was no main effect of treatment $\left(F_{(1,108)}=0.34, p=0.56\right)$, with both groups showing significant habituation to the + enantiomer. At posttest, the saline group successfully discriminated the - limonene from + limonene $\left(t_{22}=2.87, p=0.009\right)$; however, the Cogentin-treated mice showed cross-habituation, failing to discriminate the odorants $\left(t_{32}=0.41, p=0.69\right.$; Figure 2B right). In follow-up testing, the Cogentin group exhibited lower levels of investigation for the - limonene in the posttest when compared with saline controls $\left(t_{27}=3.20\right.$, $p=0.0035)$. Together these data suggest that Cogentin administration was sufficient to block the beneficial effects of enrichment on OPL.

To confirm that impairments in Cogentin-treated mice at posttest were not due to general effects of the drug on olfactory sensory function, mice were tested on a general spontaneous olfactory cross-habituation task (Cleland et al., 2002; Bath et al., 2008). For this task, mice were presented with four habituation trials each lasting $1 \mathrm{~min}$, followed by three 1 -min presentations to novel odorants delivered in a counterbalanced randomized order (Figure 2C). The novel odorants were highly similar (S1), moderately similar (S2), or dissimilar (D) to the habituated odorant (Bath et al., 2008). In total, mice were presented with five sets of odorants (see Methods for odorant sets). For each set, mice were habituated over four trials before the S1, S2, and D odorant presentations. The mean exploration time across odorant sets was calculated and is presented in Figure 2C. A two-way ANOVA of the habituation trials revealed a main effect of habituation $\left(F_{(3,76)}=6.85, p=0.0004\right)$, signifying that mice habituated to the odorant. Furthermore, there was no effect of Cogentin treatment $\left(F_{(1,76)}=2.52, p=0.12\right)$ or interaction between treatment and habituation trial $\left(F_{(3,76)}=0.16, p=0.92\right)$, suggesting that Cogentin did not impair the ability of mice to habituate to a wide variety of odorants. Next, we assessed if mice spent significantly more time investigating the S1, S2, and $\mathrm{D}$ odorants when compared with habituation trial 4 . We found that saline mice spent significantly more time investigating $S 2\left(t_{22}=2.70, p=0.013\right)$ and $D\left(t_{22}=2.12, p=0.046\right)$ but not $S 1\left(t_{22}=1.71\right.$, $\mathrm{p}=0.10$ ), whereas Cogentin-treated mice spent significantly more time investigating $\mathrm{S} 1\left(\mathrm{t}_{16}=2.32\right.$, $p=0.034)$ and $D\left(t_{16}=3.055, p=0.0076\right)$ but not $S 2\left(t_{16}=1.84, p=0.085\right)$ when compared with their respective habituation trial 4 . Importantly, saline and Cogentin mice did not differ in the time they spent investigating any of the odorants, $\mathrm{S} 1\left(\mathrm{t}_{19}=0.20, \mathrm{p}=0.85\right), \mathrm{S} 2\left(\mathrm{t}_{19}=1.55, \mathrm{p}=0.14\right)$, or $\mathrm{D}$ $\left(t_{19}=0.45, p=0.66\right)$. This suggests that impairments in perceptual learning were not due to general deficits in olfactory sensory function.

To test if olfactory enrichment and Cogentin treatment impacted $O B$ neurogenesis, all mice were administered bromodeoxyuridine (BrdU) 8 days before olfactory enrichment (Figure 2A). Following the completion of behavioral testing (28 days later), brains were collected and the density of newly born $\mathrm{BrdU}$ labeled cells in the granule cell layer of the OB was assessed. A one-way ANOVA was used to assess differences between saline-treated without olfactory enrichment, saline-treated olfactory enriched, and Cogentin-treated olfactory enriched mice (Figure 2D left). The analysis revealed a main effect of treatment $\left(F_{(2,19)}=7.97, p=0.0031\right)$ with follow-up Tukey's multiple comparison analysis detecting a significantly increased density of BrdU+ cells in saline-treated olfactory enriched mice when compared with salinetreated non-olfactory enriched mice $\left(\mathrm{t}_{19}=4.74, \mathrm{p}=0.0089\right)$. Furthermore, Cogentin-treated mice had reduced $\mathrm{BrdU}+$ cell density when compared with saline-treated enriched mice $\left(\mathrm{t}_{19}=5.07, \mathrm{p}=0.0053\right)$ but were no different than non-enriched saline-treated mice ( $\left.t_{19}=0.49, p=0.93\right)$. There was no effect of treatment on the percentage of cells that committed to a neural phenotype, as indicated by co-labeling with $\operatorname{NeuN}\left(F_{(2,19)}=0.43, p=0.65\right.$; Figure $2 \mathrm{D}$ right $)$. Together these data suggest that olfactory enrichment increases the number of BrdU+ cells in the OB, whereas Cogentin administration blocks enrichment-associated augmentation in BrdU+ cells within the OB. 
Optogenetic Stimulation of Cholinergic Projections in the Nucleus of the Horizontal Limb of the Diagonal Band of Broca Enhances Discrimination of Enantiomer Pairs

To determine if enhancing the activity of cholinergic projections to the OB is sufficient to improve perceptual discrimination, a mouse line that expresses the depolarizing optogenetic element channelrhodopsin (ChR2) under the choline acetyltransferase (ChAT) promoter was used (referred to as ChR2+ in this study) (Zhao et al., 2011). An optical fiber was surgically implanted over the right horizontal limb of the diagonal band of broca (HDB), a region rich in cholinergic neurons projecting into the $O B$, to maximize the distribution of cholinergic fibers stimulated in the $O B$ without surgically damaging the OB. One week following implantation, mice underwent the olfactory discrimination task (Figure 3A).

No differences in habituation to + limonene were observed between ChR2 + and ChR2- mice $\left(F_{(3.92)}=\right.$ 3.837, $p=0.0532$; Figure $3 \mathrm{~B}$ ), suggesting that expression of the optical channel and surgical manipulation did not alter baseline habituation. A significant effect of habituation trial was observed $\left(F_{(3.92)}=14.87\right.$, $p<0.0001$ ), with animals decreasing their investigation of + limonene as trials progressed. Furthermore, no interaction between the experimental group and habituation trial $\left(F_{(3.92)}=3.133, p=0.2161\right)$ was observed. During pretest, neither ChR2+ nor ChR2- group showed differences in time spent investigating - limonene compared with the final habituation trial (ChAT ChR2 $-t_{22}=0.58, p=0.57$; ChAT ChR2+ $\mathrm{t}_{24}=0.91, \mathrm{p}=0.37$ ) indicating a failure to discriminate. Furthermore, at pretest, the ChR2+ mice did not significantly differ in the time they spent investigating - limonene when compared with the ChR2- mice $\left(t_{23}=0.269, p=0.5749\right.$; Figure $\left.3 B\right)$. Mice then received 8-s trains of light pulses at randomly assigned frequencies (from 5 to $50 \mathrm{~Hz}$, at $5 \mathrm{~Hz}$ intervals; $5 \mathrm{~mW}$ light power) (adapted from Ma and Luo, 2012). Optogenetic stimulation was administered for $1 \mathrm{~h}$ per day for ten consecutive days, in lieu of olfactory enrichment. Following the 10-day optical stimulation paradigm, mice received a second limonene habituation and posttest session, without optical stimulation of the HDB. During the second habituation session, a significant main effect of group was observed $\left(F_{(1,92)}=5.012, p=0.0276\right)$. A significant main effect of trial $\left(F_{(3.92)}=18.95, p<0.0001\right)$, with no interaction between group and trial $\left(F_{(3.92)}=0.2552, p=0.8574\right)$, was observed, indicating that mice habituated to + limonene as the trials progressed. Importantly, at posttest, the ChAT ChR2+ group was able to discriminate the - limonene enantiomer $\left(t_{24}=2.65, p=0.014\right)$, whereas the ChAT ChR2 - group showed cross-habituation (no difference between +/- limonene investigation; $t_{22}=0.95, p=0.35$ ). Furthermore, ChR2 + mice investigated the - limonene enantiomer at a significantly higher level than ChR2 - mice during the posttest $\left(t_{23}=3.554, p=0.0017\right)$. These data suggest that optical stimulation of cholinergic neurons in the HDB, in the absence of olfactory enrichment, was sufficient to enable mice to discriminate between enantiomer pairs.

In addition to testing to $+/$ - limonene enantiomers, mice underwent olfactory discrimination testing at posttest for +/- carvone (Figure 3C) and +/- terpinen-4-ol (Figure 3D). This allowed us to assess if optogenetic effects generalized across odorants. Similar to our findings using +/ - limonene, a two-way ANOVA revealed a main effect of habituation trial for both + carvone $\left(F_{(3.92)}=16.68, p<0.0001\right)$ and + terpinen-4-ol $\left(F_{(3.92)}=7.91, p<0.0001\right)$. A main effect of treatment was also found between ChAT ChR2 - and ChAT ChR2+ during habituation to + terpinen-4-ol $\left(F_{(1.92)}=5.00, p=0.027\right)$, although a follow-up Sidak's multiple comparison test did not reveal differences between ChAT ChR2 - and ChAT ChR2 + at any given habituation trial. For both odorants, during the pretest no significant differences were observed between ChAT ChR2 - and ChAT ChR2+, nor were differences observed between the pretest and the fourth trial of the first habituation for either ChAT ChR2- or ChAT ChR2+. Following the 10-day optogenetic protocol, during the second habituation trial, a main effect was only found for habituation trial, for both + carvone $\left(F_{(3.92)}=12.24\right.$, $\mathrm{p}<0.0001)$ and + terpinen-4-ol $\left(F_{(3.92)}=16.46, p<0.0001\right)$, suggesting that mice habituated to the + enantiomers. Post testing of the - enantiomer revealed that optogenetic excitation of HDB significantly increased the investigation of the - terpinen-4-ol enantiomer $\left(t_{23}=2.42, p=0.023\right)$ but not of - carvone $\left(t_{23}=1.48, p=0.15\right)$ when compared with ChAT ChR2-. Furthermore, ChAT ChR2+ mice also showed increased investigation to - terpinen-4-ol enantiomer when compared with ChAT ChR2+ investigation of + terpinen-4-ol during the fourth trial of the second habituation ( $\left.t_{24}=2.5, p=0.019\right)$. Together these data suggest that optogenetic excitation was sufficient to significantly enhance discrimination of some, but not all, enantiomer pairs.

To determine if optical stimulation impacted $O B$ neurogenesis, mice were sacrificed, fiber placement was confirmed (Figure 3E), and the density of BrdU+ cells in the $\mathrm{OB}$ granule cell layer was quantified. Optical stimulation of cholinergic projections to the OB increased the density of BrdU+ cells in ChAT 


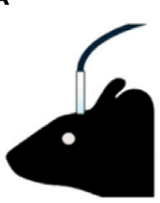

B

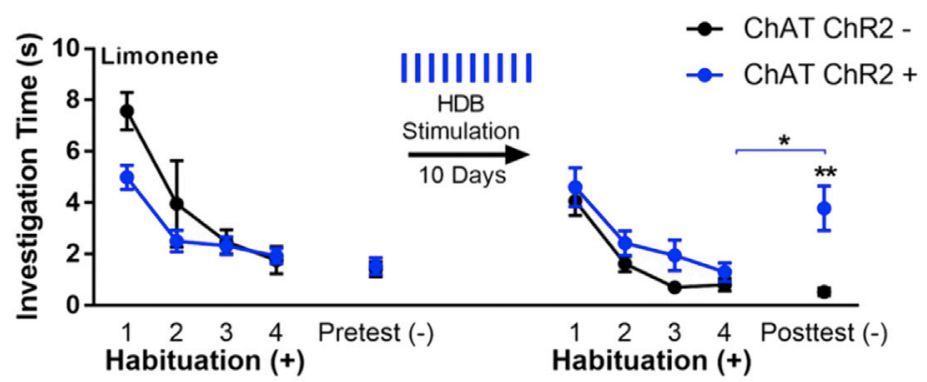

C

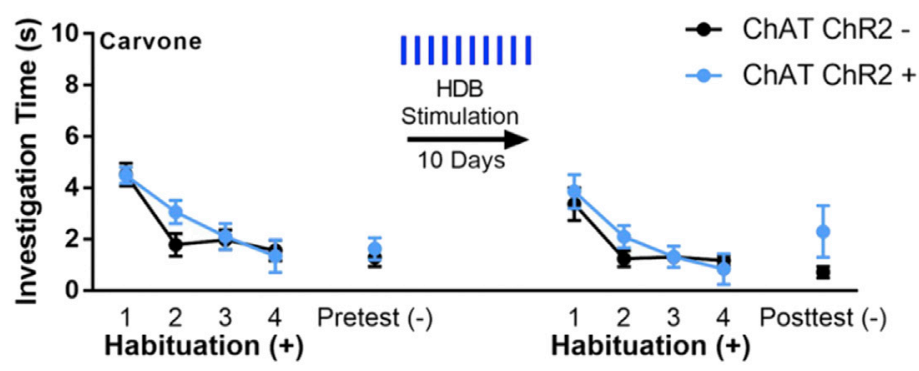

D

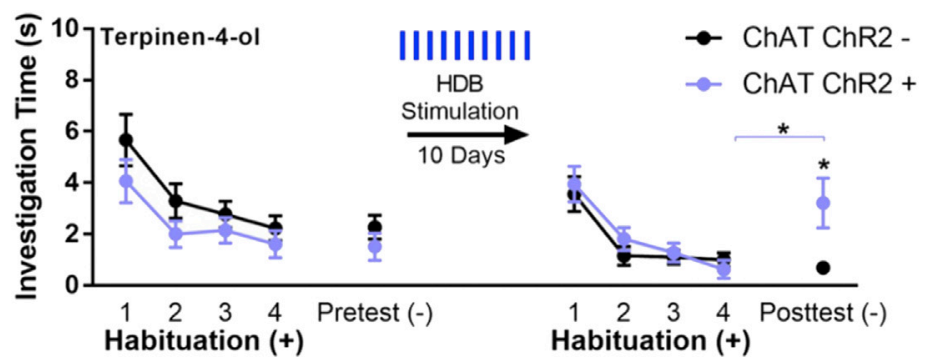

Experimental Timeline
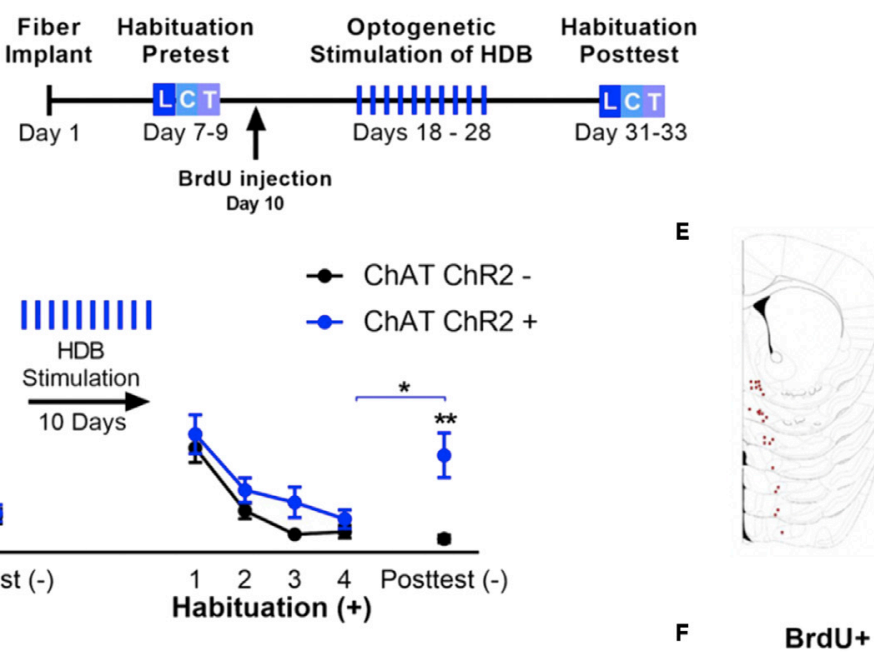

- ChAT ChR2 -

- ChAT ChR2 +

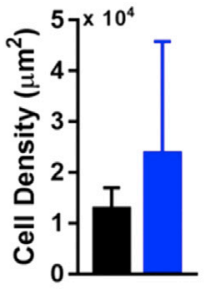

ఏ

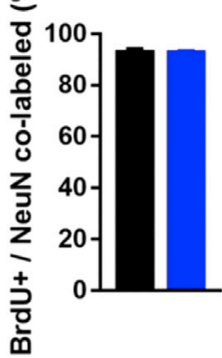

Figure 3. Optogenetic Stimulation of Cholinergic Fibers in the HDB Enables Discrimination between Limonene Enantiomers

(A) Experimental timeline.

(B) Neither ChAT ChR2+ nor ChAT ChR2 - mice were able to discriminate between the +/ - limonene enantiomers during the pretest. However, following optic stimulation of HDB (in lieu of enrichment), ChAT ChR2+ mice, but not ChAT ChR2-, were able to discriminate between + and - limonene during the posttest.

(C) Optic stimulation did not significantly increase discrimination between all enantiomer pairs. Mice were still unable to discriminate + and - carvone during the posttest.

(D) However, increased discrimination at posttest was not specific to only limonene, with mice being able to significantly discriminate between + and - terpinen-4-ol during posttest.

(E) Placement of optic fibers in HDB. ChAT ChR2 $-\mathrm{n}=12$, ChAT ChR2 $+\mathrm{n}=13$.

(F) No effects of optic stimulation were observed on the density of BrdU+ cells (top) or on the percentage of newborn cells that became neurons (bottom) ( $n=7$ per group). Data are presented as mean \pm SEM. ${ }^{\star} p<0.05,{ }^{* *} p<0.01$.

ChR2+ mice compared with ChAT ChR2 - mice that also received light pulses. However, this effect did not reach statistical significance ( $t_{12}=1.28, p=0.23$; Figure $3 \mathrm{~F}$ top). Furthermore, no differences in the percentage of cells committing to a neuronal phenotype were observed $\left(t_{12}=0.17, p=0.87\right.$; Figure $3 F$ bottom). 


\section{Blocking Adult Neurogenesis Impairs Olfactory Discrimination following Optogenetic Stimulation of HDB Cholinergic Fibers}

Acetylcholine has been shown to influence olfactory tuning and odorant discrimination (Linster et al., 2001a; Mandairon et al., 2006a; Chaudhury et al., 2009; Ma and Luo, 2012). It also influences the process of OB neurogenesis (Cooper-Kuhn et al., 2004; Kaneko et al., 2006). However, whether acetylcholine's effects on OPL depend upon the presence of newly born cells remains unknown.

Here, we found that optogenetic stimulation of HDB cholinergic projections enhanced discrimination between tested enantiomer pairs. To determine whether improvements in discrimination require the presence of newly born cells, cell proliferation in the subventricular zone (SVZ) was inhibited through administration of the mitotic blocker, cytosine arabinoside (AraC) into the right lateral ventricle (Figure 4A) during enrichment. Osmotic pump infusion of AraC was done in ChAT ChR2+ mice, allowing for the simultaneous blockade of cell division and optical stimulation of HDB fibers. The micro osmotic pump and optical fiber were implanted during the same surgery, 1 week before behavioral testing (Figure $4 A$ ). A two-way ANOVA revealed no effect of AraC treatment on habituation at pretest $\left(F_{(1,68)}=1.77, p=0.19\right.$; Figure $\left.4 B\right)$, although a main effect of trial was observed $\left(F_{(3.68)}=19.77, p<0.0001\right)$, suggesting that mice habituated to + limonene. No group by habituation trial was observed $\left(F_{(3.68)}=0.57, p=0.64\right)$, indicating similar habituation across groups. Furthermore, no significant effect was observed between pretest exploration and the last habituation trial for either group (saline $t_{18}=0.32, p=0.75$; $\mathrm{AraC}_{16}=1.006, \mathrm{p}=0.33$ ). Nor were differences in pretest observed when comparing pretest investigation times between the two groups $\left(t_{17}=1.73, p=0.102\right)$, indicating both groups were unable to discriminate + / - enantiomers at pretest. In lieu of enrichment, mice then underwent 10 days of HDB optogenetic stimulation while AraC was continuously administered. Following the end of optogenetic stimulation and AraC infusion, mice were presented with + limonene in a second habituation session. No main effects of treatment $\left(F_{(1.68)}=2.29, p=0.14\right)$ or treatment by trial interaction $\left(F_{(3.68)}=0.72, p=0.55\right)$ were observed. As expected, a main effect of trial $\left(F_{(3.68)}=10.23, p<0.0001\right)$ was found, signifying that animals significantly habituated to the odorant. Interesting, saline plus optogenetic-treated mice showed an increase in - limonene investigation $\left(t_{18}=1.99, p=0.061\right.$ ), whereas $\mathrm{AraC}$ plus optogenetic-treated mice did not show any noticeable increase in investigation at posttest $\left(t_{16}=1.45, p=0.17 ;\right.$ Figure 4B). Furthermore, the AraC ChATChR2+ mice investigated the - limonene enantiomer at significantly lower levels than the saline ChAT ChR2+ control mice $\left(t_{17}=3.17, p=0.0056\right.$; Figure 4B).

To assess if the AraC-induced suppression of optogenetically induced enantiomer discrimination was generalizable across various enantiomer pairs, mice underwent olfactory discrimination task for $+/-$ carvone (Figure 4C) and +/- terpinen-4-ol (Figure 4D). Similar to our findings with +/ - limonene, a twoway ANOVA revealed only a main effect of habituation trial for both + carvone $\left(F_{(3.68)}=17.98\right.$, $p<0.0001)$ and + terpinen-4-ol $\left(F_{(3.68)}=15.35, p<0.0001\right)$, suggesting that mice investigated the + enantiomer for lower amounts of time as trials progressed. No significant differences were observed in the investigation of - carvone between Saline/ChAT ChR2+ and AraC/ChAT ChR2+ during the pretest. However, a significant difference in the investigation time of - terpinen-4-ol was observed between Saline/ ChAT ChR2+ and AraC/ChAT ChR2+ during the pretest $\left(t_{17}=3.08, p=0.0068\right)$. Following the 10-day optogenetic stimulation of HDB, mice were presented with a second habituation session. A main effect of habituation trial was observed during the second habituation session for both + carvone $\left(F_{(3.68)}=7.39\right.$, $p=0.0002)$ and + terpinen-4-ol $\left(F_{(3.68)}=3.70, p=0.015\right)$. Suggesting that mice habituated to the + enantiomer. Furthermore, a main effect of treatment was observed during the second habituation to + carvone $\left(F_{(1.68)}=9.05, p=0.0037\right)$, suggesting that Saline/ChAT ChR2+ had greater within-session habituation when compared with the AraC/ChAT ChR2+. A post hoc Sidak's multiple comparison test did not reveal any treatment effects at any individual trial during the second habituation to + carvone. During the posttest, we found that AraC treatment was sufficient to block optogenetic-induced discrimination of the +/- enantiomers of carvone $\left(t_{17}=2.15, p=0.046\right)$ and terpinen-4-ol $\left(t_{17}=2.51, p=0.022\right)$. Furthermore, comparison of the posttest and fourth trial of the second habituation session for the saline/ChAT ChR2+ replicated findings if Figure 3, with mice showing increased investigation of the - enantiomer when compared with the + enantiomer for both carvone $\left(t_{18}=2.77, p=0.012\right)$ and terpinen-4-ol $\left(t_{18}=2.37, p=0.028\right)$. Together these data suggest that blocking mitotic division, through the use of $\mathrm{AraC}$, is sufficient to block optogenetic-induced discrimination.

To verify that AraC affected levels of neurogenesis, BrdU labeling was used. Surgical placements of micro osmotic pump cannulae and optical fibers were confirmed postmortem by sectioning brains and staining with Hema-3 (Figure 4E). AraC was found to lead to a near total loss of BrdU+ cells in the granule cell layer 
A

Experimental Timeline
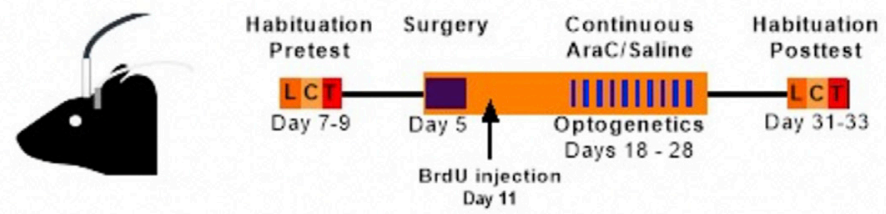

B

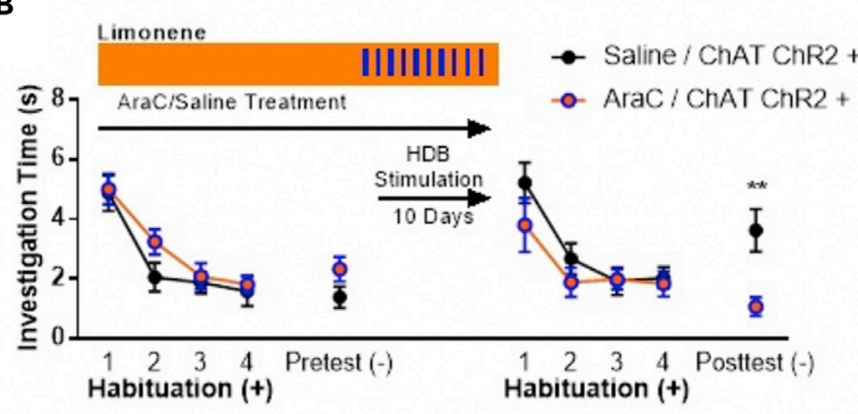

$\mathbf{E}$

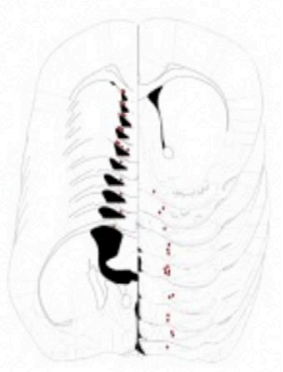

C

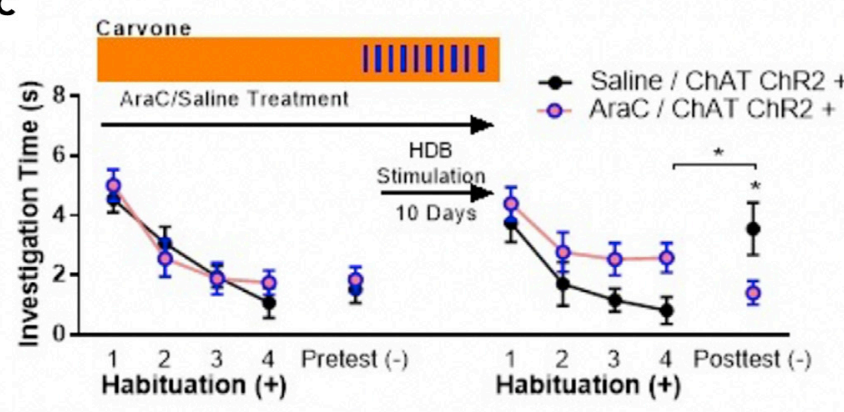

$\mathbf{F}$

BrdU+

Saline/ChAT ChR2+ AraC/ChAT ChR2+

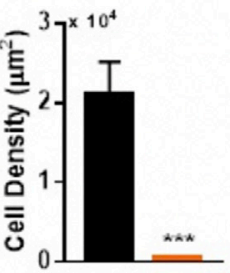

D
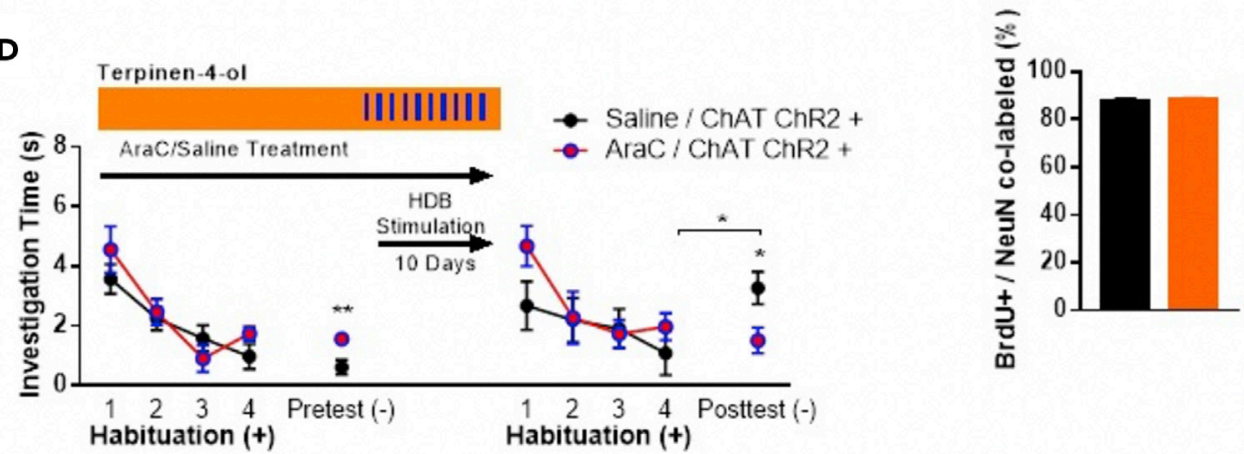

Figure 4. Suppression of Mitotic Division Blocked Optogenetically Induced Olfactory Discrimination (A) Experimental timeline.

(B-D) (B) Neither saline/ChAT ChR2+ nor AraC/ChAT ChR2+ mice were able to discriminate between the +/enantiomers during the pretest. However, following optic stimulation of the left HDB, only the saline/ChAT ChR2+ mice, but not AraC/ChAT ChR2+, were able to discriminate between + and - limonene during the posttest. Furthermore, AraC/ChAT ChR2+ also showed decreased investigation of the - enantiomer during the posttest when compared with saline/ChAT ChR2+ mice for both (C) carvone and (D) terpinen-4-ol odorants.

(E) Placement of optic fibers in the left HDB and treatment infusion pumps in the right lateral ventricle. Saline/ChAT $\mathrm{ChR} 2+\mathrm{n}=10, \mathrm{AraC} / \mathrm{ChAT} \mathrm{ChR} 2+\mathrm{n}=9$

(F) AraC treatment significantly decreased the density of $\mathrm{BrdU}+$ cells (top) but did not affect the percentage of newborn cells that become neurons (bottom) (Saline/ChAT ChR2 $+n=4$, AraC/ChAT ChR2 $+n=3$ ). Data are presented as mean \pm SEM. ${ }^{*} p<0.05,{ }^{* \star} p<0.01,{ }^{* \star *} p<0.001$ 
of the $\mathrm{OB}$ compared with saline controls $\left(t_{5}=4.38, \mathrm{p}=0.0072\right.$; Figure $4 \mathrm{~F}$ top). However, cells that were labeled with $\mathrm{BrdU}$ did not differ from the saline-treated animals in the percentage of newly born cells committing to a neuronal phenotype $\left(t_{5}=0.39, p=0.71\right.$; Figure $4 \mathrm{~F}$ bottom). Together, these results suggest that blocking mitotic division is sufficient to prevent optogenetically induced enantiomer discrimination.

\section{DISCUSSION}

In this study, we have shown that mice were able to discriminate enantiomer odorant pairs after 10 days of enrichment to both odorants. Furthermore, we have shown that blocking cholinergic activity with the cholinergic antagonist, Cogentin, was sufficient to block OPL (e.g., learned enantiomer discrimination post enrichment). Optogenetic activation of cholinergic fibers in the nucleus of the HDB was sufficient to induce enantiomer discrimination in the absence of enrichment. However, suppression of mitotic division in the lateral ventricles, via continuous infusion of $\mathrm{AraC}$, was sufficient to block the effects of HDB optogenetic activation. Together, we found that cholinergic activity is necessary for naturalistic $\mathrm{OPL}$ and that the effects of cholinergic activity require $\mathrm{OB}$ neurogenesis.

Odorant enrichment is known to enhance discrimination ability between perceptually similar odorants that activate overlapping regions in the OB (Mandairon et al., 2006b, 2006c, 2006d). This discrimination is achieved by modifying the responsiveness of mitral/tufted cells activated by the enriching odorant (Buonviso et al., 1998; Buonviso and Chaput, 1999). It is believed that the acquired ability to perceptually discriminate odorants with overlapping activation maps $(\mathrm{OPL})$ is the result of experience-dependent shifts in OB inhibitory tone (Mandairon et al., 2008) that depend on the incorporation and selective survival of newly arriving cells. Cholinergic projections to the $O B$ and regions supplying newly born cells to the $O B$ (such as the SVZ) have been found to modulate cell migration and survival. However, a role for cholinergic modulation of cell survival on OPL has yet to been shown.

Adult neurogenesis has been linked with olfactory discrimination ability, including perceptual learning. It has been proposed that the selective survival of newborn inhibitory interneurons in regions of the OB that are sensitive to the experienced odorants serve to enhance odorant discrimination. New neurons are born throughout life in the SVZ of the lateral ventricles, where OB interneurons arise (Altman, 1969). SVZ-derived cells migrate and integrate into preexisting $O B$ circuits where they differentiate into periglomerular and granule cells, the inhibitory interneurons believed to support olfactory perceptual learning (Moreno et al., 2009). It has been proposed that enrichment to a single pair of odorants, such as + and - limonene, increases interneuron survival in the part of the $O B$ responsible for detecting those enriched odorants (Moreno et al., 2012). In this example, selective interneuron survival supports perceptual discrimination within the limonene enantiomer pair. Since the regions of the $O B$ activated by limonene do not significantly overlap with those activated by carvone or terpinen-4-ol, limonene enrichment should not influence discrimination within the other tested enantiomer pairs. Here we show that olfactory enrichment to +/limonene enantiomers is sufficient to induce discrimination of the limonene enantiomer pair but not the +/- carvone or +/- terpinen-4-ol enantiomer pairs. Inconsistent with previously published work in rats (Linster et al., 2001 b), our mice were not able to discriminate +/- carvone at pretest. The discrepancies between our findings and previous work may be a result of species-specific olfactory tuning. Additional studies assessing perceptual maps of enantiomer pairs in mice will be needed to completely interpret these results.

In recent work, a number of putative mechanisms have been identified that regulate the proliferation, migration, and survival of these newly born cells (Kaneko et al., 2006; Bath et al., 2008; Scotto-Lomassese et al., 2011). Although experiments using pharmacological, radiation, or genetic techniques to dampen neurogenesis have been implicated in olfactory perceptual learning (Mouret et al., 2008; Moreno et al., 2009; Nissant et al., 2009; Alonso et al., 2012), the endogenous mechanisms regulating adult neurogenesis to support perceptual learning have remained largely unknown.

Acetylcholine can affect perceptual learning through multiple mechanisms, including long-term potentiation, altering mitral cell sensitivity, and/or effects on adult neurogenesis. We found that pharmacological inactivation of the cholinergic system through systemic administration of Cogentin was sufficient to block olfactory discrimination, whereas optogenetic activation of cholinergic fibers in the HDB was sufficient to induce olfactory discrimination in lieu of enrichment, thus providing strong evidence that manipulating the 
cholinergic system can modulate discrimination of highly similar odorants. Furthermore, manipulations of cholinergic activity were associated with significant changes in the density of newly born cells in the $O B$ granule cell layer. Although olfactory enrichment was seen to increase BrdU+ cells in the OB, blocking cholinergic activity through Cogentin administration blocked this increase in BrdU+ cell survival, with $\mathrm{BrdU}+$ cell density being indistinguishable from levels observed in mice that had not undergone olfactory enrichment.

Furthermore, blocking neurogenesis with the anti-mitotic agent, AraC, blocked any beneficial effects of cholinergic stimulation on perceptual learning, indicating that newly born cells are required to derive perceptual benefits from increased cholinergic activity. However, it is important to note that optogenetic activation of cholinergic fibers in HDB did not significantly increase BrdU+ cells. We believe that the lack of statistical significance is due to the higher variability in cell counts observed in this experiment and thus diminished power to detect meaningful differences. Additional appropriately powered replication experiments will be needed to conclusively determine the impact of cholinergic activation on BrdU+ cells in the OB.

Importantly, the results obtained were based on a task that relies on a mouse's innate ability to detect and investigate novelty. Both passive (untrained/unconditioned) and active (trained/conditioned) tasks can measure an animal's ability to discriminate between odorants; however, the results derived from the two approaches are heavily influenced by the task demands. The passive olfactory task used here provides a more naturalistic measure of olfactory sensory functioning (e.g., detection and innate motivation to investigate novel odorants in the environment), whereas reinforced tasks provide a more artificial measure of optimal performance of the system and are susceptible to the effects of overtraining and engagement of learning, memory, and reward systems (Cleland et al., 2002). The lack of reinforcement within our task may have prevented the generalization of discrimination learning and may explain some of the behavioral differences between reinforced and nonreinforced olfactory learning. Therefore, it is possible that the mechanisms governing naturalistic olfactory discrimination, described here, may not be generalizable to active learning tasks.

In summary, we provide evidence to support the theory that cholinergic projections to the OB support olfactory perceptual learning, that cholinergic activity to the $O B$ is both necessary and sufficient to enhance perceptual discrimination, and that the benefits of cholinergic activity on perceptual discrimination requires the presence of newly born cells in the OB.

\section{Limitations of the Study}

In the current work, manipulation of cholinergic activity through optogenetic manipulation, either pharmacologically or optogenetically, was shown to alter olfactory perceptual learning. More work will be needed to clarify the specific cholinergic receptors and molecular pathways supporting enhanced survival of newly born cells. Furthermore, we posit that cholinergic modulation of olfactory perceptual learning should work by enhancing coincident activity from basal forebrain cholinergic projections and activation of olfactory projection neurons stimulated by odorant in the environment to enhance selective survival of cells in regions responsive to those odorants. More work will be required to uncover the specific mechanisms supporting regionally selective survival. Finally, more work will be required to determine the permanence of these effects, e.g., how long improvements in OPL last and what mechanisms underlie degradation in the ability to discriminate odorants.

\section{METHODS}

All methods can be found in the accompanying Transparent Methods supplemental file.

\section{DATA AND CODE AVAILABILITY}

For access to raw data and or video files, please contact Dr. Kevin Bath (Kevin_Bath@Brown.edu).

\section{SUPPLEMENTAL INFORMATION}

Supplemental Information can be found online at https://doi.org/10.1016/j.isci.2019.11.016. 


\section{ACKNOWLEDGMENTS}

This project was supported by the Robert and Nancy Carney Institute for Brain Sciences-Robert and Nancy Carney gift for scientific innovation to K.G.B.; NSF Graduate Research Fellowship (DGE 0228243 to A.S.N.); and NIH Predoctoral Training Grant (T32MH020068 to A.S.N.).

\section{AUTHOR CONTRIBUTIONS}

Arielle Schilit Nitenson: collection of original data, annotation, scrubbing, interpretation, and initial use, original statistical approaches, primary data collection and analysis in coordination with supervised undergraduates, choice and refinement of methodological approaches, planning and execution of experiments, supervision of undergraduates, control validation studies in additional animal models, statistical validation, generation of original figures and visualization of optical implant locations, literature review, generation of introduction, discussion, methods, initial results.

Gabriela Manzano Nieves: 2 (scrubbing, data interpretation, and re-use), 3 (re-running of statistical analyses), 8, 9 (software for triggering of optogenetic drivers), 11 (replication and refinement of statistical tests to validate results), 12 (generation of new graphics to depict data), 13 (generation of new results section and components of discussion), 14.

Devon Poeta: 6, 8.

Ryan Bahar: 5.

Carolyn Rachofsky: 5.

Nathalie Mandairon: 1 (conceptualization of approach based on Moreno et al., 2012 and application to cholinergic system, discussion throughout experiments to refine approach and interpretation), 14.

Kevin Bath: 1, 4, 6, 7, 8, 10, 11, 13 (generation of components of original draft - pieces of methods, introduction, discussion), 14.

\section{DECLARATION OF INTERESTS}

The authors declare no competing interests.

Received: May 2, 2019

Revised: September 23, 2019

Accepted: November 6, 2019

Published: December 20, 2019

\section{REFERENCES}

Alonso, M., Lepousez, G., Sebastien, W., Bardy, C., Gabellec, M.-M., Torquet, N., and Lledo, P.-M (2012). Activation of adult-born neurons facilitates learning and memory. Nat. Neurosci. 15, 897-904.

Altman, J. (1969). Autoradiographic and histological studies of postnatal neurogenesis. IV. Cell proliferation and migration in the anterior forebrain, with special reference to persisting neurogenesis in the olfactory bulb. J. Comp. Neurol. 137, 433-457.

Altman, J., and Das, G.D. (1965).

Autoradiographic and histological evidence of postnatal hippocampal neurogenesis in rats.

J. Comp. Neurol. 124, 319-335.

Bath, K.G., Mandairon, N., Jing, D., Rajagopal, R., Kapoor, R., Chen, Z.-Y., Khan, T., Proenca, C.C. Kraemer, R., Cleland, T.A., et al. (2008). Variant brain-derived neurotrophic factor (Val66Met) alters adult olfactory bulb neurogenesis and spontaneous olfactory discrimination.

J. Neurosci. 28, 2383-2393.

Bolden, C., Cusack, B., and Richelson, E. (1992). Antagonism by antimuscarinic and neuroleptic compounds at the five cloned human muscarinic cholinergic receptors expressed in Chinese hamster ovary cells. J. Pharmacol. Exp. Ther. 260, 576-580.

Buonviso, N., and Chaput, M. (1999). Olfactory experience decreases responsiveness of the olfactory bulb in the adult rat. Neuroscience 95 , 325-332.

Buonviso, N., Gervais, R., Chalansonnet, M., and Chaput, M. (1998). Short-lasting exposure to one odour decreases general reactivity in the olfactory bulb of adult rats. Eur J Neurosci 10, 2472-2475.
Castillo, P.E., Carleton, A., Vincent, J.D., and Lledo, P.M. (1999). Multiple and opposing roles of cholinergic transmission in the main olfactory bulb. J. Neurosci. 19, 9180-9191.

Chaudhury, D., Escanilla, O., and Linster, C. (2009). Bulbar acetylcholine enhances neural and perceptual odor discrimination. J. Neurosci. 29, $52-60$

Cleland, T.A., and Linster, C. (2012). On-center/ inhibitory-surround decorrelation via intraglomerular inhibition in the olfactory bulb glomerular layer. Front. Integr. Neurosci. 6, 5.

Cleland, T.A., and Sethupathy, P. (2006). Nontopographical contrast enhancement in the olfactory bulb. BMC Neurosci. 7, 7.

Cleland, T.A., Morse, A., Yue, E.L., and Linster, C (2002). Behavioral models of odor similarity. Behav. Neurosci. 116, 222-231. 
Cooper-Kuhn, C.M., Winkler, J., and Kuhn, H.G. (2004). Decreased neurogenesis after cholinergic forebrain lesion in the adult rat. J. Neurosci. Res. 77, 155-165.

Fletcher, M.L., and Wilson, D.A. (2002). Experience modifies olfactory acuity: acetylcholine-dependent learning decreases behavioral generalization between similar odorants. J. Neurosci. 22, RC201.

Freedman, S.B., Beer, M.S., and Harley, E.A (1988). Muscarinic M1, M2 receptor binding. Relationship with functional efficacy. Eur. J. Pharmacol. 156, 133-142.

Gheusi, G. and Lledo, P.-M. (2014). Adult neurogenesis in the olfactory system shapes odor memory and perception. Prog. Brain Res. 208, 157-175.

Heimer, L., Zahm, D.S., and Schmued, L.C. (1990). The basal forebrain projection to the region of the nuclei gemini in the rat; a combined light and electron microscopic study employing horseradish peroxidase, fluorescent tracers and Phaseolus vulgaris-leucoagglutinin Neuroscience 34, 707-731.

Kaneko, N., Okano, H., and Sawamoto, K. (2006). Role of the cholinergic system in regulating survival of newborn neurons in the adult mouse dentate gyrus and olfactory bulb. Genes Cells 11 1145-1159.

Linster, C., and Cleland, T.A. (2002). Cholinergic modulation of sensory representations in the olfactory bulb. Neural Netw. 15, 709-717.

Linster, C., and Cleland, T.A. (2009). Glomerular microcircuits in the olfactory bulb. Neural Netw. 22, 1169-1173.

Linster, C., and Hasselmo, M. (1997). Modulation of inhibition in a model of olfactory bulb reduces overlap in the neural representation of olfactory stimuli. Behav. Brain Res. 84, 117-127.

Linster, C., Garcia, P.A., Hasselmo, M.E., and Baxter, M.G. (2001a). Selective loss of cholinergic neurons projecting to the olfactory system increases perceptual generalization between similar, but not dissimilar, odorants. Behav. Neurosci. 115, 826-833.

Linster, C., Johnson, B.A., Yue, E., Morse, A., Xu, Z., Hingco, E.E., Choi, Y., Choi, M., Messiha, A., and Leon, M. (2001b). Perceptual correlates of neural representations evoked by odorant enantiomers. J. Neurosci. 21, 9837-9843.

Ma, M., and Luo, M. (2012). Optogenetic activation of basal forebrain cholinergic neurons modulates neuronal excitability and sensory responses in the main olfactory bulb. J. Neurosci. 32, 10105-10116.

Mandairon, N., Didier, A., and Linster, C. (2008). Odor enrichment increases interneurons responsiveness in spatially defined regions of the olfactory bulb correlated with perception. Neurobiol. Learn Mem. 90, 178-184.

Mandairon, N., Ferretti, C.J., Stack, C.M., Rubin, D.B., Cleland, T.A., and Linster, C. (2006a). Cholinergic modulation in the olfactory bulb influences spontaneous olfactory discrimination in adult rats. Eur. J. Neurosci. 24, 3234-3244.

Mandairon, N., Stack, C., Kiselycznyk, C., and Linster, C. (2006b). Broad activation of the olfactory bulb produces long-lasting changes in odor perception. Proc. Natl. Acad. Sci. U S A 103 13543-13548.

Mandairon, N., Stack, C., and Linster, C. (2006c). Olfactory enrichment improves the recognition of individual components in mixtures. Physiol. Behav. 89, 379-384.

Mandairon, N., Stack, C., Kiselycznyk, C., and Linster, C. (2006d). Enrichment to odors improves olfactory discrimination in adult rats. Behav. Neurosci. 120, 173-179.

Moreno, M.M. Linster, C., Escanilla, O. Sacquet, J., Didier, A., and Mandairon, N. (2009). Olfactory perceptual learning requires adult neurogenesis Proc. Natl. Acad. Sci. U S A 106, 17980-17985.

Moreno, M.M., Bath, K., Kuczewski, N., Sacquet, J. Didier, A., and Mandairon, N. (2012). Action of the noradrenergic system on adult-born cells is required for olfactory learning in mice.

J. Neurosci. 32, 3748-3758.

Mori, K., Nagao, H., and Yoshihara, Y. (1999). The olfactory bulb. coding and processing of odor molecule information. Science 286, 711-715.

Mouret, A., Gheusi, G., Gabellec, M.-M., de Chaumont, F., Olivo-Marin, J.-C., and Lledo, P.-M. (2008). Learning and survival of newly generated neurons: when time matters. J. Neurosci. 28, 11511-11516.

Nissant, A., Bardy, C., Katagiri, H., Murray, K., and Lledo, P.-M. (2009). Adult neurogenesis promotes synaptic plasticity in the olfactory bulb. Nat. Neurosci. 12, 728-730.

Nusser, Z., Kay, L.M., Laurent, G., Homanics, G.E., and Mody, I. (2001). Disruption of GABA(A) receptors on GABAergic interneurons leads to increased oscillatory power in the olfactory bulb network. J. Neurophysiol. 86, 2823-2833.

Paez-Gonzalez, P., Asrican, B., Rodriguez, E., and Kuo, C.T. (2014). Identification of distinct ChAT+ neurons and activity-dependent control of postnatal SVZ neurogenesis. Nat. Neurosci. 17, 934-942.

Restrepo, D. (2009). Symposium overview: the neural basis of odor perception. Ann. N. Y. Acad. Sci. 1170, 275-276.

Scotto-Lomassese, S., Nissant, A., Mota, T., Neant-Fery, M., Oostra, B.A., Greer, C.A., Lledo, P.M., Trembleau, A., and Caille, I. (2011). Fragile X mental retardation protein regulates new neuron differentiation in the adult olfactory bulb. J. Neurosci. 31, 2205-2215.

Sharma, G. (2013). The dominant functional nicotinic receptor in progenitor cells in the rostral migratory stream is the $\alpha 3 \beta 4$ subtype. J. Neurophysiol. 109, 867-872.

Stopfer, M., Bhagavan, S., Smith, B.H., and Laurent, G. (1997). Impaired odour discrimination on desynchronization of odour-encoding neural assemblies. Nature 390, 70-74.

Tan, J., Savigner, A., Ma, M., and Luo, M. (2010). Odor information processing by the olfactory bulb analyzed in gene-targeted mice. Neuron 65 , 912-926.

Wilson, D.A., and Stevenson, R.J. (2003) Olfactory perceptual learning: the critical role of memory in odor discrimination. Neurosci. Biobehav. Rev. 27, 307-328.

Zhao, S., Ting, J.T., Atallah, H.E., Qiu, L., Tan, J. Gloss, B., Augustine, G.J., Deisseroth, K., Luo, M., Graybiel, A.M., et al. (2011). Cell type-specific channelrhodopsin-2 transgenic mice for optogenetic dissection of neural circuitry function Nat Methods 8,745-752. 
ISCI, Volume 22

Supplemental Information

\section{Acetylcholine Regulates Olfactory \\ Perceptual Learning through Effects \\ on Adult Neurogenesis}

Arielle Schilit Nitenson, Gabriela Manzano Nieves, Devon Lynn Poeta, Ryan Bahar, Carolyn Rachofsky, Nathalie Mandairon, and Kevin G. Bath 


\section{Transparent Methods}

Subjects

A total of 77,8 to 12 week old, male WT and ChAT ChR2 EYFP mice [B6.Cg-Tg(ChatCOP4*H134R/EYFP,Slc18a3) 6Gfng/J; RRID: IMSR_JAX:014546;(Zhao et al., 2011)] on a C57B16/N

background (Charles River Laboratories, Wilmington, MA) were used for this study. All mice were bred in-house. Mice were housed on a $12 \mathrm{~h}$ light/ $12 \mathrm{~h}$ dark cycle with food and water provided ad libitum. Testing occurred during the first half of the light phase of the light/dark cycle.

\section{Odorants Preparation}

For olfactory perceptual learning (cross-habituation and enrichment), stimulus odorants were diluted in the odorless carrier, mineral oil, to 0.1 Pascal (Pa) vapor pressure. For spontaneous olfactory discrimination, stimulus odorants were diluted in mineral oil to $0.01 \mathrm{~Pa}$. Dilution volumes were acquired through analysis of vapor pressures using ACD ChemSketch software (Advanced Chemistry Development, Toronto, Ontario, Canada). For olfactory perceptual learning tasks, + limonene (habituation) and - limonene (test) odorants were used. For spontaneous olfactory discrimination tasks, five sets of odorants were used:

1. N-hexyl acetate (Hab), N-amyl acetate (S1), N-butyl acetate (S2), Anisole (D)

2. Propanoic acid (C3) (Hab), Butanoic acid (C4) (S1), Pentanoic acid (C5) (S2), 5-methylfurfural (D)

3. Octanal (Hab), Heptanal (S1), Hexanal (S2), Anisole (D)

4. Octanoic acid (C8) (Hab), Heptanoic acid (C7) (S1), Hexanoic acid (C6) (S2), (R)-(+)-limonene (D)

5. Pentanol (Hab), Hexanol (S1), Heptanol (S2), Citronellal (D)

\section{Cross-Habituation Task: Olfactory Perceptual Learning}

Mice were individually positioned in polycarbonate cages before testing. For each trial, odorants were introduced by placing $100 \mu \mathrm{l}$ of an odorant onto a piece of filter paper (Whatman, Florham Park, NJ) and suspending the filter paper in each mouse's cage by enclosing the paper in a tea ball hanging in the 
upper corner of the cage. During the four habituation trial, mice were exposed to $0.1 \mathrm{~Pa}$ of a habituation odorant. For the test trials, the enantiomer to the habituation odorant was presented in lieu of the habituation odorant. Each trial was one minute in length followed by a five-minute inter-trial interval. Fresh odorants and filter paper were used in each trial. All trials were videotaped using Ethovision XT 8.5 tracking software (Noldus), after which investigation time was manually scored with the rater blind to drug group or genotype and odorant identity.

Enantiomer pairs were chosen for their perceptual similarity and the inability of our mice to behaviorally distinguish them in our pretest data (Linster et al., 2001b). Enantiomer pairs (one habituation odorant and its enantiomer) were used in each behavioral experiment. For consistency, the + form of the enantiomer pair was always used in the habituation trial and the - form was always used in the enantiomer trial.

\section{Cross-Habituation Task: Spontaneous Olfactory Discrimination}

Each mouse was placed individually into a polycarbonate cage. For each trial, the odorants were presented by introducing $100 \mu \mathrm{L}$ of $0.01 \mathrm{~Pa}$ diluted odorant onto a piece of filter paper (Whatman, Florham Park, NJ), and placing the filter paper inside a tea ball (Table S2). The tea ball was subsequently draped inside the upper corner of the cage. The mice were presented with a single aliphatic acid odorant on four consecutive trials (habituation). Three novel odorant trials followed, where three odorants were introduced in a counter-balanced randomized order: a highly similar ( $\mathrm{S} 1$ - differing by a single unbranched hydrocarbon from the habituation odorant), moderately similar (S2 - differing by two unbranched hydrocarbons from the habituation odorant) and dissimilar odorant ( $\mathrm{D}$ - structurally and perceptually unique odorant). All trials were one minute long with a five-minute inter-trial interval. This procedure was repeated with five different odorant sets over the course of five days. Following manual scoring, the five days of testing were averaged, and the data was pooled by trial type and drug group or genotype to assess the effects of drug group or genotype on odorant detection, habituation and discrimination. 


\section{Bromodeoxyuridine Injections}

To test if any of our manipulations altered the density of surviving newly born cells, we injected mice with BrdU (IP: $50 \mathrm{mg} / \mathrm{kg}$ ) three times at two-hour intervals on the day following the final pretest. We allowed labeled cells eight days to migrate from their birthplace in the SVZ to the OB (Winner et al., 2002) before beginning olfactory manipulation. Thirty-nine days post-BrdU injection, mice were sacrificed, and we used immunohistochemistry and stereological counting to test for the effects of enrichment on newborn cell survival in the OB granule cell layer. To quantify the density of BrdU-positive cells in the granule cell layer of the olfactory bulb, an optical fractionator method was used. Every third serially obtained section (80 $\mu \mathrm{m}$ interval) was mounted and processed immunohistochemically to detect BrdU. Sections were counterstained with Nissl and a reference volume of the granule cell layer was traced using a stereology system (Stereoinvestigator; MicroBrightField, Willis- ton, VT). BrdU-positive nuclei were counted within a $20 \times 20 \times 30 \mu \mathrm{m}$ counting frame, which randomly sampled within a $122.8 \times 68.9 \mu \mathrm{m}$ randomized counting grid using a meander scanning technique. BrdU-positive cells throughout the $z$-plane were counted; those that contacted the lateral or upper exclusion plane remained uncounted. The total number of cells counted were divided into the number of counting frames sampled multiplied by the size of the counting frame to obtain an estimate of the density of BrdU-positive cells within this structure.

\section{Drug Administration}

To determine if the activity of cholinergic receptors during olfactory enrichment is necessary for olfactory perceptual learning, mice were administered Cogentin $(25 \mathrm{mg} / \mathrm{kg}$ in saline; Enzo Life Sciences, Farmingdale, NY), a selective M1 muscarinic acetylcholine receptor antagonist, or saline, intraperitoneally 20 minutes prior to each enrichment session (10 injections total over 10 days).

\section{Optogenetic Surgery}

For the optogenetics experiments, we used eight to 12 week old ChAT ChR2 EYFP male mice. Transgenic and control $(\mathrm{C} 57 \mathrm{~B} 16 / \mathrm{N})$ mice were injected intraperitoneally with the analgesic buprenorphine hydrochloride 20 minutes before surgery [0.1 mg/kg, Buprenex Injectable, Reckitt Benckiser Healthcare 
(UK) Ltd., Hull, England]. Mice were anesthetized using an isoflurane-oxygen mixture (induction $=2-3 \%$, maintenance $=1-2.5, \mathrm{O}_{2}$ flow rate $=75 \mathrm{ppm}$ ), shaved and placed in a stereotaxic apparatus (David Kopf Instruments, Tujunga, CA). A craniotomy was made on the skull above the coordinates for the left HDB $\left(\mathrm{AP}=+0.3 \mathrm{~mm}, \mathrm{ML}=-2.0 \mathrm{~mm}, 13^{\circ}\right.$ lateral to medial), and an optical fiber was implanted $(\mathrm{DV}=5.0 \mathrm{~mm}$; fiber made in-house, core diameter $=200 \mu \mathrm{m}, \mathrm{NA}=0.22$ ). The fiber was fixed in place using $\mathrm{C} \& \mathrm{~B}$ Metabond Quick Adhesive Cement System (Parkell Inc., Edgewood, NY) and dental acrylic (Repair Resin Quick Set Lab Pack, All 4 Dentist by Interguide Dental \& Medical Supply, Burlingame, CA).

\section{Osmotic pump Surgery}

For the AraC experiment, in addition to the optogenetic implant, mice were implanted subcutaneously with a micro osmotic pump (Model 1002, ALZET Osmotic Pumps, Cupertino, CA). The pump was connected via polyvinyl tubing to a cannulae aimed at the right subventricular zone (SVZ; AP = $+1.2 \mathrm{~mm}, \mathrm{ML}=+0.9 \mathrm{~mm}, \mathrm{DV}=3.0 \mathrm{~mm}$; brain infusion kit 3, ALZET Osmotic Pumps, Cupertino, CA). The pump was filled with $100 \mu \mathrm{L}$ cytosine- $\beta$-d-arabinofuranoside (AraC; $4 \%$ in $0.9 \%$ saline solution, Sigma Aldrich, St. Louis, MO) with a flow rate of $0.25 \mu \mathrm{L}$ per hour (Moreno et al., 2012). Post-surgery observations were maintained for three days.

\section{Optogenetic Stimulation}

Each mouse received one hour of laser stimulation every day for 10 consecutive days (in lieu of olfactory enrichment). In the first optogenetic experiment (Figure 3B), stimulation was achieved by coupling a patch cord (Doric Lenses, Quebec, Canada) to a blue light diode laser (MBL-III-473, 100mW, OptoEngine, LLC, Midvale, UT), measuring approximately $5 \mathrm{~mW}$ at tip of implanted fiber. In the second optogenetic experiment (Figure 4B), stimulation was achieved by coupling a patch cord (manufactured inhouse) to a blue LED (PlexBright LED Module, 24.9mW, Plexon, Dallas, TX), measuring approximately $5 \mathrm{~mW}$ at tip of implanted fiber. In both experiments, each optogenetic stimulation session began with a 10 second habituation period, followed by eight-second trains of light pulses with 23 -second intervals between 
each train. For each train of light pulses, we randomly assigned a frequency (from $5-50 \mathrm{~Hz}$, at $5 \mathrm{~Hz}$ intervals) using MATLAB coupled to an Arduino. Each pulse lasted for $15 \mathrm{~ms}$ (protocol adapted from Ma and Luo, 2012).

Statistics

We used two-way ANOVAs to analyze the habituation sessions. When necessary, follow-up posthoc sidak multiple comparison tests were used. For all other comparisons, two-tailed student's $t$-tests were used. All data is presented in graphs and figures as mean \pm SEM. Statistical analysis was performed using Prism Graphpad or SPSS software. Graphs were made using Prism Graphpad software. 